\title{
BMJ Open Cohort profile: The Swedish National Register of Urinary Bladder Cancer (SNRUBC) and the Bladder Cancer Data Base Sweden (BladderBaSe)
}

Christel Häggström, ${ }^{1,2}$ Fredrik Liedberg, ${ }^{3,4}$ Oskar Hagberg, ${ }^{5}$ Firas Aljabery, ${ }^{6}$
Viveka Ströck, ${ }^{7}$ Abolfazl Hosseini, ${ }^{8}$ Truls Gårdmark, ${ }^{9}$ Amir Sherif, ${ }^{10}$
Per-Uno Malmström, ${ }^{1}$ Hans Garmo, ${ }^{11,12}$ Staffan Jahnson, ${ }^{6}$ Lars Holmberg ${ }^{1,11}$
To cite: Häggström C, Liedberg F, Hagberg 0 et al. Cohort profile: The Swedish National Register of Urinary Bladder Cancer (SNRUBC) and the Bladder Cancer Data Base Sweden (BladderBaSe). BMJ Open 2017;7:e016606. doi:10.1136/ bmjopen-2017-016606

- Prepublication history and additional material for this paper are available online. To view these files please visit the journal online (http://dx.doi. org/10.1136/bmjopen-2017016606).

Received 24 February 2017

Revised 5 July 2017

Accepted 19 July 2017

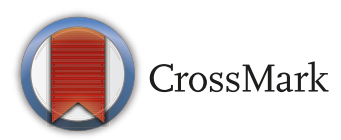

For numbered affiliations see end of article.

Correspondence to Dr Christel Häggström; christel.haggstrom@umu.se

\section{ABSTRACT}

Purpose To monitor the quality of bladder cancer care, the Swedish National Register of Urinary Bladder Cancer (SNRUBC) was initiated in 1997. During 2015, in order to study trends in incidence, effects of treatment and survival of men and women with bladder cancer, we linked the SNRUBC to other national healthcare and demographic registers and constructed the Bladder Cancer Data Base Sweden (BladderBaSe).

Participants The SNRUBC is a nationwide register with detailed information on $97 \%$ of bladder cancer cases in Sweden as compared with the Swedish Cancer Register. Participants in the SNRUBC have registered data on tumour characteristics at diagnosis, and for $98 \%$ of these treatment data have been captured. From 2009, the SNRUBC holds data on $88 \%$ of eligible participants for follow-up 5 years after diagnosis of non-muscle invasive bladder cancer, and from 2011, data on surgery details and complications for $85 \%$ of participants treated with radical cystectomy. The BladderBaSe includes all data in the SNRUBC from 1997 to 2014, and additional covariates and follow-up data from linked national register sources on comorbidity, socioeconomic factors, detailed information on readmissions and treatment side effects, and causes of death.

Findings to date Studies based on data in the SNRUBC have shown inequalities in survival and treatment indication by gender, regions and hospital volume. The BladderBaSe includes 38658 participants registered in SNRUBC with bladder cancer diagnosed from 1 January 1997 to 31 December 2014. The BladderBaSe initiators are currently in collaboration with researchers from the SNRUBC investigating different aspects of bladder cancer survival.

Future plans The SNRUBC and the BladderBaSe project are open for collaborations with national and international research teams. Collaborators can submit proposals for studies and study files can be uploaded to servers for remote access and analysis. For more information, please contact the corresponding author.
Strengths and limitations of this study

- The Swedish National Register of Urinary Bladder Cancer (SNRUBC) is used for monitoring the quality of care of bladder cancer and has captured data on $97 \%$ of bladder cancer cases in Sweden in the period 1997-2014. We linked data in the SNRUBC to national healthcare and demographic registers and constructed the Bladder Cancer Data Base Sweden (BladderBaSe).

- To our knowledge, with 38658 cases based on an unselected population with very high coverage from an entire nation, BladderBaSe forms the largest and most comprehensive clinical bladder cancer database.

- In addition to bladder cancer tumour characteristics and treatment, the BladderBaSe includes information on comorbidity, socioeconomic factors, detailed information on readmissions and treatment side effects, and causes of death.

- We have no information or systematic evaluation of the $3 \%$ with bladder cancer not registered in the SNRUBC and no validation studies of the data in the SNRUBC against individual patient records.

\section{INTRODUCTION}

Bladder cancer imposes an important health problem worldwide; it is the fourth most common cancer among men in developed countries, ${ }^{1}$ with no improvement in survival over the last decades, ${ }^{23}$ in addition to a high cost of treatment on a per-patient basis. ${ }^{4}$

The Swedish National Register of Urinary Bladder Cancer (SNRUBC) was initiated in 1997 to register all new cases of bladder cancer with detailed information on tumour location, size and extension (tumour, node, metastases classification of malignant tumours), grade, and primary treatment. The SNRUBC registration expanded in 2009 to register data from 5-year follow-up of non-muscle invasive bladder cancer, and 
in 2011 to register data on radical cystectomy. The main aim of the SNRUBC is quality assurance of bladder cancer healthcare; a secondary aim is to use the data for clinical research. Examples of quality indicators monitored by the SNRUBC are lead times and proportions of patients seen at multidisciplinary conferences. The SNRUBC is administered by the Regional Cancer Centre (RCC) in each of the six healthcare regions in Sweden and collated to a national register.

In 2015, we linked the SNRUBC to a number of national healthcare and demographic registers to construct the Bladder Cancer Data Base Sweden (BladderBaSe). The aim was to create a comprehensive cohort of patients with bladder cancer to study trends in incidence, effects of treatment, and overall as well as disease-specific survival, with detailed data on patient and tumour characteristics, treatment, socioeconomic factors and comorbidity.

\section{COHORT DESCRIPTION}

\section{Swedish National Register of Urinary Bladder Cancer}

In Sweden, new histologically, cytologically or clinically diagnosed tumours are mandated by law to be reported to the national Swedish Cancer Registry. ${ }^{5}$ All new diagnoses of a tumour in the bladder with International Classification of Diseases for Oncology, 3rd revision (ICD-O-3) code C67.0-C67.6 and C67.8-C67.9 for individuals 18 years or older are additionally requested to be reported into the SNRUBC. Data are collected by the six RCCs, which report to the national databases for the Swedish Cancer Registry and the SNRUBC. The records are validated and checked for completeness by each RCC. In the period 1997-2014 the coverage of bladder cancer cases in the SNRUBC was $97 \%$ as compared with the Swedish Cancer Register with regional variation from $92 \%$ to $100 \%$ (figure 1 ).

Patient records in the SNRUBC are standardised into four forms with data on (1) characteristics of the primary tumour at diagnosis; (2) primary treatment; (3) follow-up at 5 years after diagnosis for non-muscle invasive bladder cancer; and (4) preoperative, perioperative and postoperative events in conjunction with radical cystectomy. The number of participants and the coverage of the four registration forms in the SNRUBC from 1997 to 2014 are shown in figure 2. In short, all participants have registered data on diagnosis, and of these $98 \%$ have data on treatment; of the eligible participants with non-muscle invasive bladder cancer, $88 \%$ have data on 5-year follow-up, and of eligible participants treated with radical cystectomy $85 \%$ have registered details of the surgery, complications and reoperations.

The forms for tumour information at diagnosis and treatment have been in use since the initiation in 1 January 1997. From 1 January 2009, participants with non-muscle invasive bladder cancer (stage Ta, Tis or T1) without metastases are registered with data on time to relapse, progress and death 5 years after date of diagnosis (ie, for participants with year of diagnosis 2004 and forward). ${ }^{6}$ From 1 January 2011, detailed data on radical cystectomy are registered with surgical details, complications and reoperations up to 90 days postoperatively according to the Clavien-Dindo classification of surgical complications. $^{78}$

An overview of variables registered in the four standardised registration forms in the SNRUBC is listed in table 1. Detailed information on variables and captured ratios from 1997 to 2014 in the four forms are shown in online supplementary tables 1-4. In addition, the radical cystectomy form includes data on complications and reoperations within 90 days of the surgery, shown in online supplementary table 5 .

\section{Bladder Cancer Data Base Sweden}

In 2015, data on participants in the SNRUBC with date of registration from 1 January 1997 to 31 December 2014 were linked to a number of healthcare and demographic registries at the National Board of Health and Welfare and the Statistics Sweden by use of the personal identification number (PIN) to form the BladderBaSe (figure 3). The PIN is a unique 10-digit number assigned to each individual in the Swedish population, and allows for virtually $100 \%$ coverage in the Swedish healthcare system. ${ }^{9}$ Participants in the BladderBaSe have been assigned an internal identification (ID) number, for which the key between the PIN and internal ID number is kept exclusively by Statistics Sweden. Participants with no date of diagnosis or less than 18 years of age at date of diagnosis were excluded. Last day of follow-up for participants in the BladderBaSe was date of death, date of emigration or 31 December 2014, whichever happened first.

The BladderBaSe includes information from 28814 men and 9844 women with bladder cancer. Baseline characteristics of participants registered and lost to follow-up in the four standardised registration forms in the SNRUBC are shown in online supplementary table 6. An overview of variables retrieved from each register is shown in table 2. More details of each register and selected variables are described below.

\section{The Patient Register}

The Swedish Patient Register is administered by the National Board of Health and Welfare and includes nationwide information regarding inpatient and outpatient care from 1987. Each record holds dates of admission and discharge, hospital unit, procedures and diagnoses coded according to the ICD-9 or ICD-10. ${ }^{10}$ The Charlson Comorbidity Index (CCI) was calculated with data from the Patient Register to estimate the concomitant disease burden of the participants in BladderBaSe. The CCI is based on a list of diseases with a specific weight assigned to each disease category. The separate weights are collated to an overall score, categorised into 0 for no comorbidity, 1 for mild comorbidity, 2 for intermediate and 3 or more for severe comorbidity. ${ }^{11}$ For participants with metastatic bladder cancer at date of diagnosis, data on metastatic cancer was not included in 


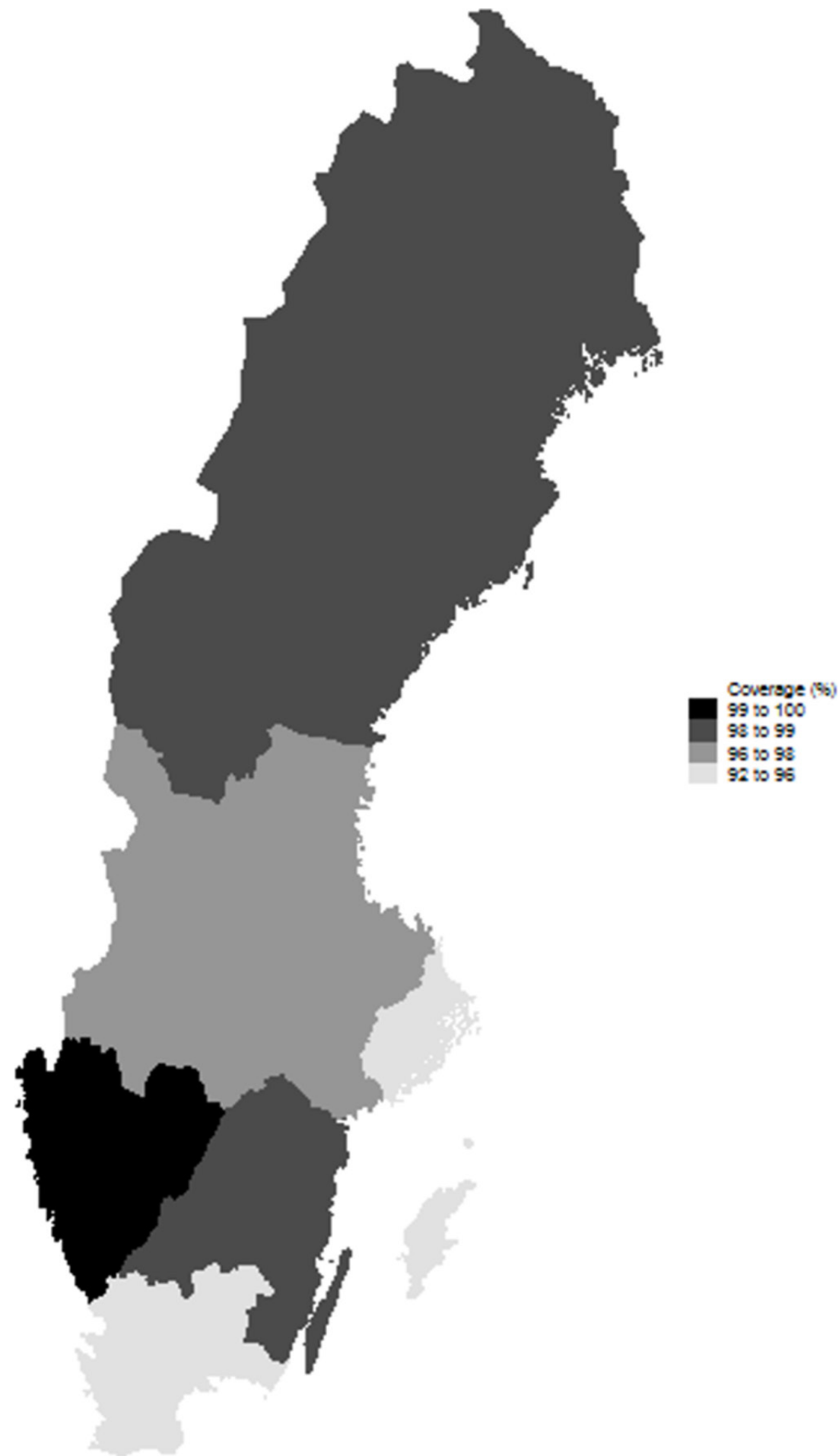

Figure 1 Coverage of bladder cancer in the Swedish National Register of Urinary Bladder Cancer, separately for the six healthcare regions in Sweden, as compared with the Swedish Cancer Register.

the calculations of CCI. A validation study of the Patient Register reported high validity for most diagnoses, with a positive predictive value of $85 \%-95 \% .{ }^{12}$ Furthermore, data were retrieved both prior to and after the date of bladder cancer diagnosis from the Patient Register on risk factors for bladder cancer, risk factors of treatment side effects, and/or modifiers of treatment response and natural history of the disease. Examples of such data are urinary tract infections, type 2 diabetes mellitus, chronic obstructive pulmonary disease and prior abdominal or pelvic surgery.

The Cancer Register

The Swedish Cancer Register was initiated 1958 and has due to mandatory reporting high validity. ${ }^{13}$ We retrieved data on all other cancer diagnoses and their dates, 


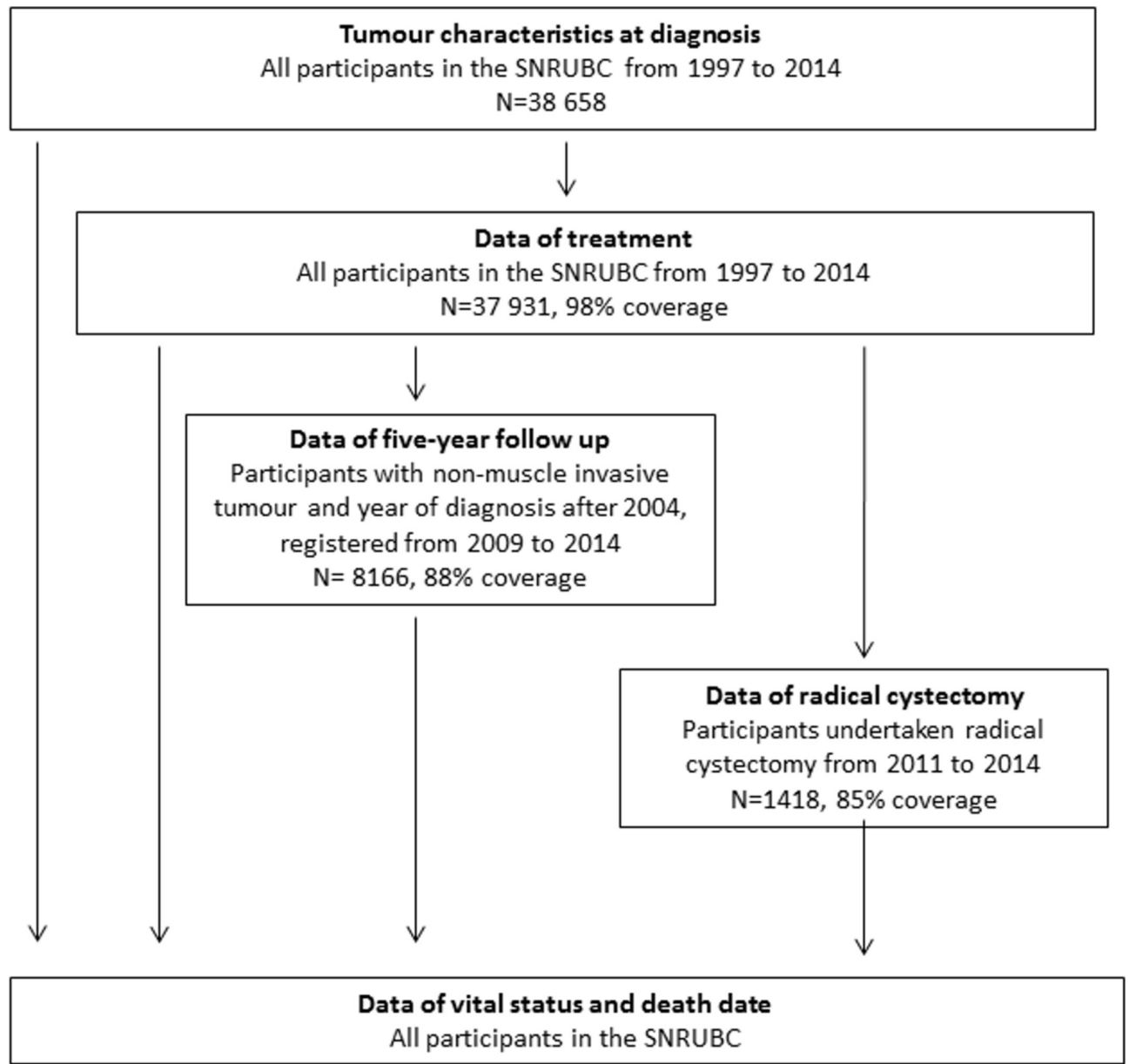

Figure 2 Flow diagram of data collected in the Swedish National Register of Urinary Bladder Cancer (SNRUBC), with number of participants and capture rates from 1997 to 2014.

Table 1 Overview of data included in the four standardised forms in the Swedish National Register of Urinary Bladder Cancer

Registration form
Tumour characteristics at
diagnosis

Treatment

Data recorded

Reporter information: hospital and department

Tumour information: TNM stage, grade, tumour diameter, number of tumours, histology and morphological codes

Dates of: diagnosis, referral, received referral, first visit to specialist and TUR/px

Alternatives for referral reason and morphological confirmation

Reporter information: hospital and department

Primary investigation options: data on multidisciplinary conference, single-dose

chemotherapy and reresection

Date and details of given treatment: intravesical instillations, systemic chemotherapy,

radical cystectomy, radiotherapy or other treatments

Five-year follow-up for non- Reporter information: hospital and department

muscle invasive bladder cancer

Status and date of recurrence and progression

Radical cystectomy

Reporter information: hospital and department

Preoperative data: TNM stage, weight, height, body mass index, American Society of

Anesthesiologists score, previous pelvic surgery, radiation or neoadjuvant chemotherapy

Perioperative data: type of surgery, type of lymphadenectomy, type of urinary diversion,

blood loss, duration of surgery, accidental organ injury during surgery

Postoperative data: complications, reoperations and readmissions within 90 days, length of hospital stay, pathological T stage, number of excised lymph nodes, and number of excised and metastatic lymph nodes 


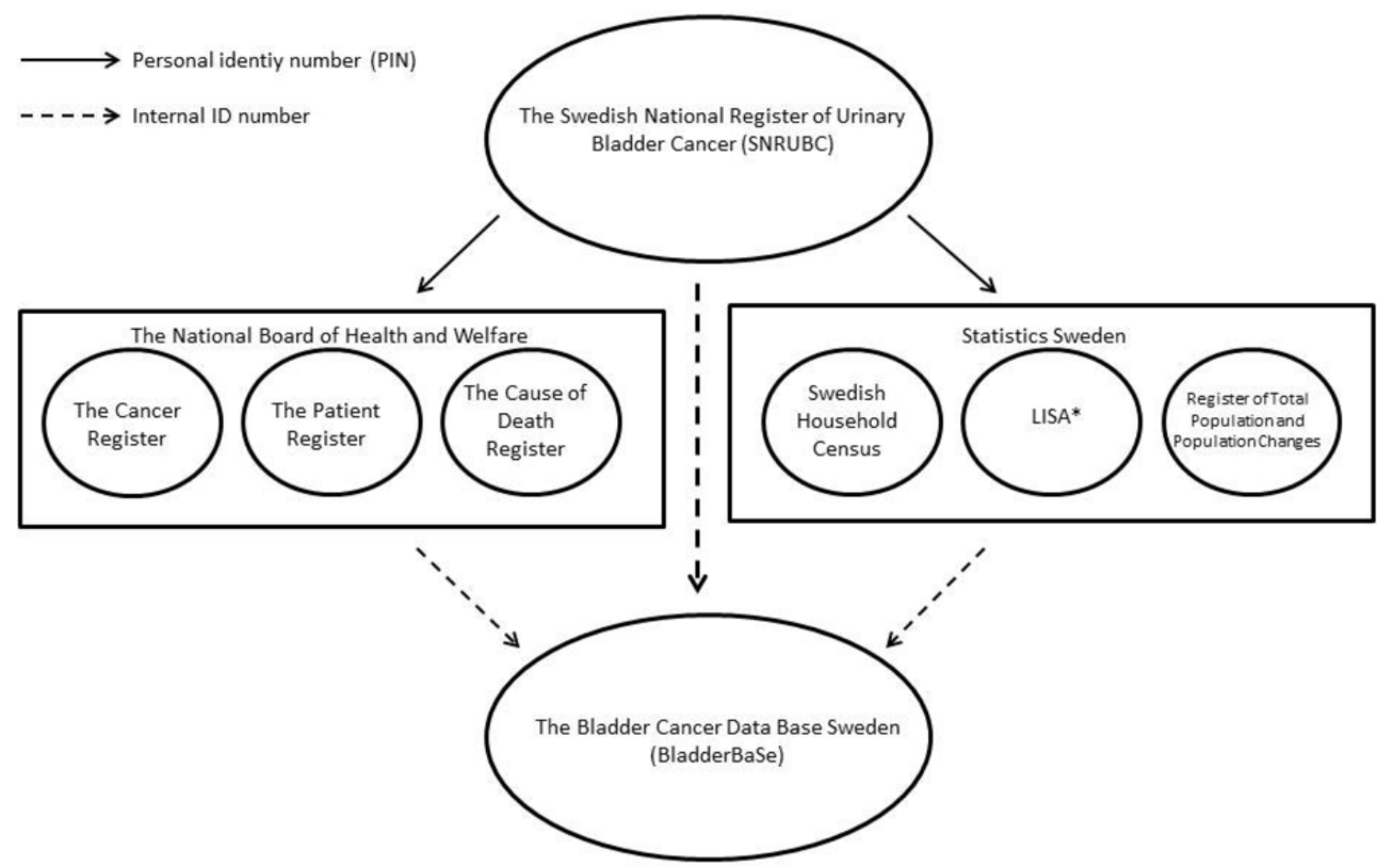

Figure 3 Data from the Swedish National Register of Urinary Bladder Cancer (SNRUBC) were linked to nationwide healthcare and demographic registries to construct the Bladder Cancer Data Base Sweden (BladderBaSe). *Longitudinal Integration Database for Health Insurance and Labour Market Studies.

Table 2 Retrieved register information from nationwide healthcare and demographic registries included in the Bladder Cancer Data Base Sweden

\begin{tabular}{|c|c|}
\hline National registries & Retrieved data \\
\hline The Cancer Register & Data on cancer diagnoses including site and date \\
\hline The Patient Register & $\begin{array}{l}\text { Inpatient and outpatient data with data on diagnoses, medical } \\
\text { procedures and surgeries }\end{array}$ \\
\hline The Causes of Death Register & Date of death, and underlying and contributing causes of death \\
\hline Swedish Household Census & Data from 1990 of socioeconomic status and profession \\
\hline Register of Total Population and Population Changes & $\begin{array}{l}\text { Personal identification number of all Swedish residents and their } \\
\text { country of birth; data on immigration and emigration }\end{array}$ \\
\hline
\end{tabular}

irrespective of date of bladder cancer diagnosis for all participants in the BladderBaSe.

\section{The Causes of Death Register}

From the Causes of Death Register we retrieved data on underlying and contributing causes of death and dates of death. The Causes of Death Register was initiated in 1953, and the proportion of missing death certificates in 2014 was $1 \% .^{14}$

Swedish Household Census and the Register of Total Population and Population Changes

From the Statistics Sweden we retrieved data from the Register of Total Population and Population Changes and the Swedish Household Census on marital status, country of birth, dates of immigration and emigration. ${ }^{15}$
Furthermore, we retrieved data from the Swedish Household Census from year 1990 on socioeconomic status based on the Swedish Socio-Economic Index and profession.

Longitudinal Integration Database for Health Insurance and Labour Market Studies

The Longitudinal Integration Database for Health Insurance and Labour Market Studies (LISA) database administered by the Statistics Sweden holds annual registers from 1990 of data based on the labour market, educational and social sectors. The LISA database has information at an individual level, and at group level such as families, companies and places of employment. From the LISA database we retrieved information about socioeconomic 
Table 3 Descriptive statistics at date of diagnosis of participants included in the Bladder Cancer Data Base Sweden (BladderBaSe)

\begin{tabular}{|c|c|c|c|c|}
\hline & \multicolumn{2}{|c|}{ Men ( $n=28$ 814) } & \multicolumn{2}{|c|}{ Women $(n=9844)$} \\
\hline & $\mathbf{N}$ & $\%$ & $\mathbf{N}$ & $\%$ \\
\hline \multicolumn{5}{|l|}{ Year of diagnosis } \\
\hline 1 January 1997 to 31 December 2002 & 8610 & 30 & 3062 & 31 \\
\hline 1 January 2003 to 31 December 2008 & 9405 & 33 & 3138 & 32 \\
\hline 1 January 2009 to 31 December 2014 & 10799 & 37 & 3644 & 37 \\
\hline \multicolumn{5}{|l|}{ Type of bladder cancer } \\
\hline Non-muscle invasive & 21330 & 74 & 6734 & 68 \\
\hline Muscle invasive & 6920 & 24 & 2891 & 29 \\
\hline T stage $X$ or missing & 564 & 2 & 219 & 2 \\
\hline \multicolumn{5}{|l|}{ Age at diagnosis } \\
\hline Less than 65 years & 6653 & 23 & 2306 & 23 \\
\hline $65-69$ years & 4257 & 15 & 1272 & 13 \\
\hline 70-74 years & 5110 & 18 & 1412 & 14 \\
\hline $75-79$ years & 5227 & 18 & 1734 & 18 \\
\hline 80-84 years & 4349 & 15 & 1600 & 16 \\
\hline 85 years and above & 3218 & 11 & 1520 & 15 \\
\hline \multicolumn{5}{|l|}{ Marital status } \\
\hline Married & 18118 & 63 & 3888 & 39 \\
\hline Divorced & 3959 & 14 & 1593 & 16 \\
\hline Unmarried & 2859 & 10 & 904 & 9 \\
\hline Widowed & 3570 & 12 & 3383 & 34 \\
\hline Missing & 308 & 1 & 76 & 1 \\
\hline \multicolumn{5}{|l|}{ Education level ${ }^{*}$} \\
\hline Low & 12944 & 45 & 4641 & 47 \\
\hline Intermediate & 10118 & 35 & 3286 & 33 \\
\hline High & 4833 & 17 & 1467 & 15 \\
\hline Missing & 919 & 3 & 450 & 5 \\
\hline \multicolumn{5}{|c|}{ Charlson Comorbidity Index prior to diagnosis $†$} \\
\hline No comorbidity (0) & 16274 & 56 & 6413 & 65 \\
\hline Mild comorbidity (1) & 5034 & 17 & 1549 & 16 \\
\hline Intermediate comorbidity (2) & 4154 & 14 & 1066 & 11 \\
\hline Severe comorbidity (3 or more) & 3352 & 12 & 816 & 8 \\
\hline
\end{tabular}

*Educational level categorised as low ( $\leq 9$ years of school), intermediate (10-12 years) and high ( $\geq 13$ years), corresponding to mandatory school, high school and college or university.

†Charlson Comorbidity Index is calculated during a 10-year period prior to diagnosis. Comorbidity scores for metastatic cancer are not included in the Charlson Comorbidity Index for participants with metastatic bladder cancer at date of diagnosis.

variables such as educational level, profession, annual family and individual income.

\section{Findings to date}

A list of publications based on the SNRUBC is shown in online supplementary table 7 . The SNRUBC steering committee has published annual reports online, and from 2011 separate reports for radical cystectomy. ${ }^{67}$

In the SNRUBC, female gender has been associated with more aggressive tumours, less probability of optimal treatment and shorter survival, in comparison to men. ${ }^{16}$
Time trends over 15 years in SNRUBC revealed a rising mean age at diagnosis, a larger proportion of non-muscle invasive tumours and no improvement of survival. ${ }^{3}$ Studies on muscle invasive bladder cancer showed that curative treatment was less likely to be given at low-volume as compared with high-volume hospitals, for female gender as compared with male gender, and for older patients as compared with younger. ${ }^{17}$ Studies on non-muscle invasive bladder cancer showed large regional variations of disease progression 5 years after diagnosis, ${ }^{18}$ an underuse 
of bacillus Calmette-Guérin (BCG) for stage T1 bladder cancer, ${ }^{19}$ and large regional variations in treatment of stage Ta and T1 bladder cancer. ${ }^{20}$ Studies on radical cystectomy have shown high risk of complications within 90 days for long surgery duration and higher patient age, ${ }^{21}$ and a higher reoperation rate for patients receiving a continent diversion as compared with an ileal conduit. ${ }^{22}$ Moreover, patients treated with radical cystectomy at high-volume hospitals had longer survival and lower risk of local recurrence as compared with patients treated at low-volume hospitals, ${ }^{23}$ and university hospitals more often used continent reconstruction as urinary diversion after radical cystectomy as compared with county hospitals, but with regional variations. ${ }^{24}$

In BladderBaSe, $24 \%$ of male and $29 \%$ of the female participants were diagnosed with muscle invasive bladder cancer. Tabulated information of other variables at diagnosis is shown in table 3. Data on education level and marital status were retrieved at date of diagnosis, and data on CGI were calculated based on data from 10 years' time prior to date of diagnosis. The BladderBaSe project group in collaboration with researchers from the SNRUBC is currently investigating survival after a diagnosis of muscle invasive bladder cancer, readmissions and side effects after radical cystectomy, temporal and regional trends of treatment, and survival for non-muscle invasive bladder cancer.

\section{STRENGTHS AND LIMITATIONS}

To our knowledge, with 38658 cases based on an unselected population in a register with very high coverage from an entire nation, BladderBaSe forms the largest clinical bladder cancer database. The main strengths of the BladderBaSe are detailed information on tumour characteristics, treatments and follow-up, and in addition data on important confounding factors such as socioeconomic variables and comorbidity. The main weaknesses are the lacking information on the $3 \%$ with bladder cancer not registered in the SNRUBC and no validation studies of the data in the SNRUBC against individual patient records.

\section{COLLABORATION}

The steering group of the SNRUBC and the project group working with the BladderBaSe are open for collaboration with national and international research teams. Collaborators can propose and apply for studies in the BladderBaSe using a standardised form. After approved application, the project data administrators upload study-specific files with selected variables to a server for statistical analysis through remote access. Users of this system will be charged for software licences, data administration and for preprocessing of study files.

Studies within the aim of the BladderBaSe as stated in the introduction have approval from Research Ethics Board and included registries. Collaborators who wish to study other objectives need to apply to the Research
Ethics Board. When reporting studies from BladderBaSe, authors are encouraged to use the STrengthening the Reporting of OBservational studies in Epidemiology (STROBE) checklist for cohort studies. For more information of collaboration with the SNRUBC or the BladderBaSe, contact the corresponding author $(\mathrm{CH})$, email: christel.haggstrom@umu.se.

\section{Author affiliations}

${ }^{1}$ Department of Surgical Sciences, Uppsala University, Uppsala, Sweden

${ }^{2}$ Department of Biobank Research, Umeå University, Umeå, Sweden

${ }^{3}$ Department of Urology, Skåne University Hospital, Malmö, Sweden

${ }^{4}$ Department of Translational Medicine, Lund University, Malmö, Sweden

${ }^{5}$ Regional Cancer Centre South, Lund, Sweden

${ }^{6}$ Department of Clinical and Experimental Medicine, Division of Urology, Linköping University, Linköping, Sweden

${ }^{7}$ Department of Urology, Sahlgrenska University Hospital, Gothenburg, Sweden

${ }^{8}$ Department of Urology, Karolinska University Hospital, Stockholm, Sweden

${ }^{9}$ Department of Clinical Sciences, Danderyd Hospital, Karolinska Institute,

Stockholm, Sweden

${ }^{10}$ Department of Surgical and Perioperative Sciences, Urology and Andrology, Umeå University, Umeå, Sweden

${ }^{11}$ Division of Cancer Studies, Faculty of Life Sciences and Medicine, King's College London, London, UK

${ }^{12}$ Regional Cancer Centre Uppsala/Örebro, Uppsala, Sweden

Acknowledgements This project was made possible with help of the data collected in the SNRUBC, and we would like to thank the members of the SNRUBC: VS, FA, Johan Johansson, P-UM, Malcolm Carringer, AH, TG, AS, Roland Rux, Markus Johansson, Petter Kollberg, Anna-Karin Lind, Jenny Wanegård, Magdalena Cwikiel, Elisabeth Överholm, Anders Ullen, Erika Jonsson, Helena Thulin, Gun Danielsson, Helene Hummer, Fredrik Liedberg, and SJ. We also thank Pär Stattin for guidance in with database administration.

Contributors $\mathrm{CH}, \mathrm{FL}, \mathrm{SJ}$ and $\mathrm{LH}$ initiated the study and drafted the manuscript. $\mathrm{FL}, \mathrm{FA}, \mathrm{VS}, \mathrm{AH}, \mathrm{TG}, \mathrm{AS}, \mathrm{P}-\mathrm{UM}$ and $\mathrm{SJ}$ contributed with data, and $\mathrm{CH}, \mathrm{OH}$ and $\mathrm{HG}$ analysed data. All authors revised the manuscript and approved the final version to be published.

Funding This work was supported by the Swedish Cancer Society, grant number CAN 2013/472.

Competing interests None declared.

Ethics approval This study was approved by the Research Ethics Board at Uppsala University, Sweden.

Provenance and peer review Not commissioned; externally peer reviewed.

Data sharing statement Annual reports from the SNRUBC are available online at http://www.cancercentrum.se/vast/cancerdiagnoser/urinvagar/urinblase-ochurinvagscancer/ kvalitetsregister/. Collaborators can propose and apply for studies in the BladderBaSe using a standardised form. After approved application, the project data administrators can upload study-specific files with selected variables to a server for statistical analysis through remote access. Users of this system will be charged for software licences, data administration and for preprocessing of study files. For more information contact the corresponding author.

Open Access This is an Open Access article distributed in accordance with the Creative Commons Attribution Non Commercial (CC BY-NC 4.0) license, which permits others to distribute, remix, adapt, build upon this work non-commercially, and license their derivative works on different terms, provided the original work is properly cited and the use is non-commercial. See: http://creativecommons.org/ licenses/by-nc/4.0/

C Article author(s) (or their employer(s) unless otherwise stated in the text of the article) 2017. All rights reserved. No commercial use is permitted unless otherwise expressly granted.

\section{REFERENCES}

1. Jemal A, Bray F, Center MM, et al. Global cancer statistics. CA Cancer J Clin 2011;61:69-90. 
2. Bryan RT, Kirby R, O'Brien T, et al. So much cost, such little progress. Eur Urol 2014;66:263-4.

3. Jahnson S, Hosseini Aliabad A, Holmäng S, et al. Swedish National Registry of Urinary Bladder Cancer: No difference in relative survival over time despite more aggressive treatment. Scand J Urol 2016;50:14-20.

4. Kaplan AL, Litwin MS, Chamie K. The future of bladder cancer care in the USA. Nat Rev Urol 2014;11:59-62.

5. The National Board of Health and Welfare. National Cancer Register. 2015 http://www.socialstyrelsen.se/register/halsodataregister/ cancerregistret

6. Regionala Cancercentrum i Samverkan. Nationellt kvalitetsregister för urinblåsecancer. Nationell Rapport Blåscancerregistret, 2015 http:// www.cancercentrum.se/vast/cancerdiagnoser/urinvagar/urinblaseoch-urinvagscancer/kvalitetsregister/

7. Regionala Cancercentrum i Samverkan. Nationellt kvalitetsregister för urinblåsecancer. Nationell Rapport Cystektomiregistret, 2014 http:// www.cancercentrum.se/vast/cancerdiagnoser/urinvagar/urinblaseoch-urinvagscancer/kvalitetsregister/

8. Dindo D, Demartines N, Clavien PA. Classification of surgical complications: a new proposal with evaluation in a cohort of 6336 patients and results of a survey. Ann Surg 2004;240:205-13.

9. Ludvigsson JF, Otterblad-Olausson P, Pettersson BU, et al. The Swedish personal identity number: possibilities and pitfalls in healthcare and medical research. Eur J Epidemiol 2009;24:659-67.

10. The National Board of Health and Welfare. The National Patient Register, 2015 http://www.socialstyrelsen.se/register/ halsodataregister/patientregistret

11. Charlson ME, Pompei P, Ales KL, et al. A new method of classifying prognostic comorbidity in longitudinal studies: development and validation. J Chronic Dis 1987:40:373-83.

12. Ludvigsson JF, Andersson E, Ekbom A, et al. External review and validation of the Swedish national inpatient register. BMC Public Health 2011:11:450.

13. Barlow L, Westergren K, Holmberg L, et al. The completeness of the Swedish Cancer Register: a sample survey for year 1998. Acta Oncol 2009;48:27-33.
14. The National Board of Health and Welfare. Causes of Death, 2014 http://www.socialstyrelsen.se/publikationer2015/2015-8-1

15. Ludvigsson JF, Almqvist C, Bonamy AK, et al. Registers of the Swedish total population and their use in medical research. Eur $J$ Epidemiol 2016;31:125-36.

16. Thorstenson A, Hagberg O, Ljungberg B, et al. Gender-related differences in urothelial carcinoma of the bladder: a populationbased study from the Swedish National Registry of Urinary Bladder Cancer. Scand J Urol 2016;50:292-7.

17. Jahnson S, Damm O, Hellsten S, et al. A population-based study of patterns of care for muscle-invasive bladder cancer in Sweden. Scand J Urol Nephrol 2009;43:271-6.

18. Liedberg F, Hagberg O, Holmäng S, et al. Local recurrence and progression of non-muscle-invasive bladder cancer in Sweden: a population-based follow-up study. Scand J Urol 2015;49:290-5.

19. Patschan $\mathrm{O}$, Holmäng $\mathrm{S}$, Hosseini $\mathrm{A}$, et al. Use of bacillus CalmetteGuérin in stage T1 bladder cancer: Long-term observation of a population-based cohort. Scand J Urol 2015;49:127-32

20. Gårdmark T, Bladström A, Hellsten $\mathrm{S}$, et al. Analysis of clinical characteristics, management and survival of patients with Ta T1 bladder tumours in Sweden between 1997 and 2001. Scand J Urol Nephrol 2006;40:276-82.

21. Jerlström $\mathrm{T}$, Gårdmark $\mathrm{T}$, Carringer $\mathrm{M}$, et al. Urinary bladder cancer treated with radical cystectomy: perioperative parameters and early complications prospectively registered in a national populationbased database. Scand J Urol 2014;48:334-40.

22. Sabir EF, Holmäng S, Liedberg F, et al. Impact of hospital volume on local recurrence and distant metastasis in bladder cancer patients treated with radical cystectomy in Sweden. Scand J Urol 2013;47:483-90.

23. Liedberg F, Holmberg E, Holmäng $\mathrm{S}$, et al. Long-term follow-up after radical cystectomy with emphasis on complications and reoperations: a Swedish population-based survey. Scand J Urol Nephrol 2012;46:14-18.

24. Jahnson S, Damm O, Hellsten S, et al. Urinary diversion after cystectomy for bladder cancer: a population-based study in Sweden. Scand J Urol Nephrol 2010;44:69-75. 